\title{
MYC Positive
}

National Cancer Institute

\section{Source}

National Cancer Institute. MYC Positive. NCI Thesaurus. Code C131061.

Indicates that MYC expression has been detected in a sample. 